\title{
Determining the Capacity of Unloading Bulk Cargo Terminal Using Queuing Theory
}

\author{
Ugljesa Bugaric ${ }^{1,}{ }^{*}$ - Dusan Petrovic ${ }^{1}$ - Zoran Petrovic ${ }^{2}$ - Miroslav Pajcin ${ }^{3}$ - Gordana Markovic-Petrovic 4 \\ ${ }^{1}$ University of Belgrade, Faculty of Mechanical Engineering, Serbia \\ 2 Tecon Sistem d.o.o., Serbia \\ 3 Jugoimport SDPR, Serbia \\ 4 DZ-Zemun, Serbia
}

Hierarchical structure of the system, river terminals for bulk cargo unloading, connected with queuing and servicing and stochastic character of the input/output values are underlined. The approach using the queuing theory is developed for engineering use as simpler, faster and more convenient than the approach using simulation. Results obtained using the queuing theory and previously obtained results using simulation modelling are shown alongside. The obtained results can be used at the beginning of the design process when rough estimations of the system behaviour are needed. Some of the obtained results are applied and verified on the existing system.

(C) 2011 Journal of Mechanical Engineering. All rights reserved.

Keywords: bulk cargo, unloading, river terminal, queuing theory

\section{INTRODUCTION}

Work of the ports with its optimal capacity assumes a prompt accommodation of vessels with minimal waiting time in the port and with maximal use of berth facilities. The capacity of a port generally depends on the number of berths available to ship traffic and cargo handling capacity. The terminal for bulk cargo unloading can stand alone as a specialized terminal or can be a part of a port. Specialized stand alone river terminal for unloading bulk cargo (i.e. river terminal) presents the organization of different activities, connected with the control and handling of material flow from the vessel to the transport or the storage system of the technological installations, which provides maximal servicing of vessels with minimum expenses. Those river terminals are mostly used in electrical plants for coal unloading, in steel mills for unloading of iron ore and coal and in chemical plants for unloading of raw materials etc. Terminals of this kind have a big unloading rate, which is their main characteristic.

Bulk cargoes, which are to be unloaded differ by granulation and density. Materials are relatively dry so that they do not compose compact mass and they can take shape of the cargo space of vessel. Very important characteristics of those materials are the fact that the cost of transportation and manipulation is an important part of their final value. [3]

This paper aims at determining the capacity of the unloading bulk cargo terminal using the queuing theory. The same topic with a different approach (simulation) was previously discussed and analysed in [3]. In addition to the new approach (queuing theory), the difference between obtained results using the queuing theory and previously obtained results using simulation are discussed and underlined.

The approach using the queuing theory is developed for engineering use as a simpler and faster and in this way more convenient for the use in the starting phases of the design process than the approach using simulation.

In this new analytical approach, two different models of the river terminal are still used. The first model is when unloading devices are working without strategy (i.e. model 1), while the second model is when unloading devices are working with strategy (i.e. model 2).

Therefore, the system modelling used in this paper is basically the same with system modelling in [3], with changes needed due to the queuing theory model limitations.

The examples of port modelling can be found in works of Agerschou et al. [1], Comer et

*Corr. Author's Address: University of Belgrade, Faculty of Mechanical Engineering, 
al. [5], El Sheikh et al. [7], Kondratowicz [9], Park et al. [11], Sinowczik [12].

\section{SYSTEM MODELLING}

In some areas of design practice there is a strong opinion that the design premises are known and unchangeable, such as electronics and mechanics where the characteristics and structure of materials and goods as well as the environment are known. While in the design of technical and technological systems of material flow (ports, specialized terminals, distribution centres, storages etc.) this is not the case. Design premises, such as: the number of barges in tows, different bulk cargoes in barges, the distance between anchorage and the berth, water level, meteorological conditions, are usually unknown and changeable, which means that the stochastic behaviour is present. This is also the case in the design of river terminals [3].

The above mentioned facts as well as the possibiliy of an occurrence of a natural phenomena, stochastic changes in water and land transport, failure in work of unloading mechanization and other involved equipment which are also stochastic indicate that the only way to design such systems is to use the stochastic approach.

The data needed for this paper were gained from an existing river terminal for bulk cargo unloading on river Danube. A simplified layout of this terminal is shown in Fig. 1 [2]

Modelling and design of the river terminal is not possible for the whole system at once, so first decomposition of the system must be done. Some sub-systems must be analyzed and designed separately and after this the modelling of the whole system can be done according to the parameters, which are gained through the behaviour of the sub-systems. There is a strong hierarchical structure of the terminal meaning that the output of the hierarchically lower sub-systems is usually input for the hierarchically upper subsystems. Hierarchical structure and levels of river terminal is shown in Fig. 2.

The river terminal usually consists of two sub-systems: »anchorage « and »vessel-operative coast «, due to the problem of the material flow.

The sub-system "vessel-operative coast " consists of three basic sub-systems: »unloading mechanization «, »conveyor« and »storage«. The basic sub-system »unloading mechanization« contains two elementary sub-systems »crane«. The »crane« elementary sub-system is hierarchically the lowest and represents knot point (bottleneck) for the material flow system. The unloading bridge with a grab and hopper on it represents, in this case, the elementary sub-system »crane $\ll$.

Simplified servicing procedure, due to limitations of the queuing theory models, in the

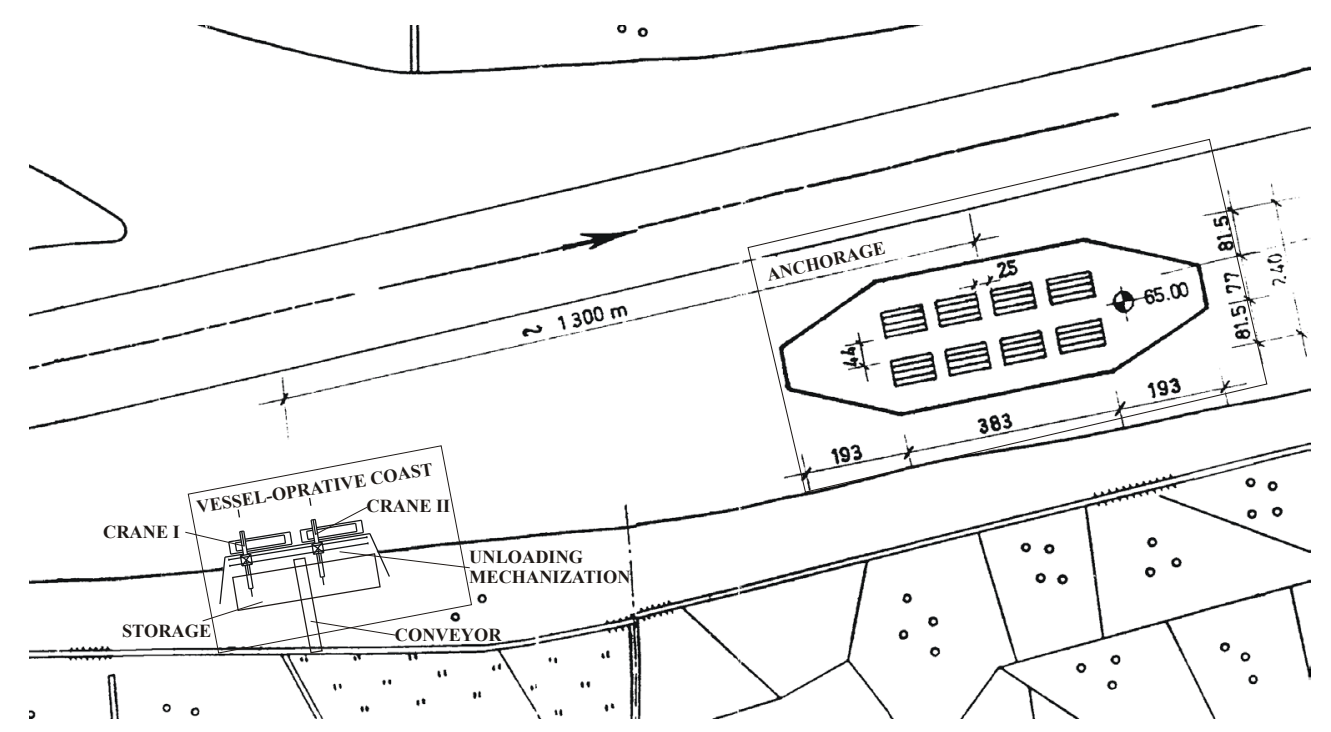

Fig. 1. Terminal for bulk cargo unloading on river Danube - existing situation 


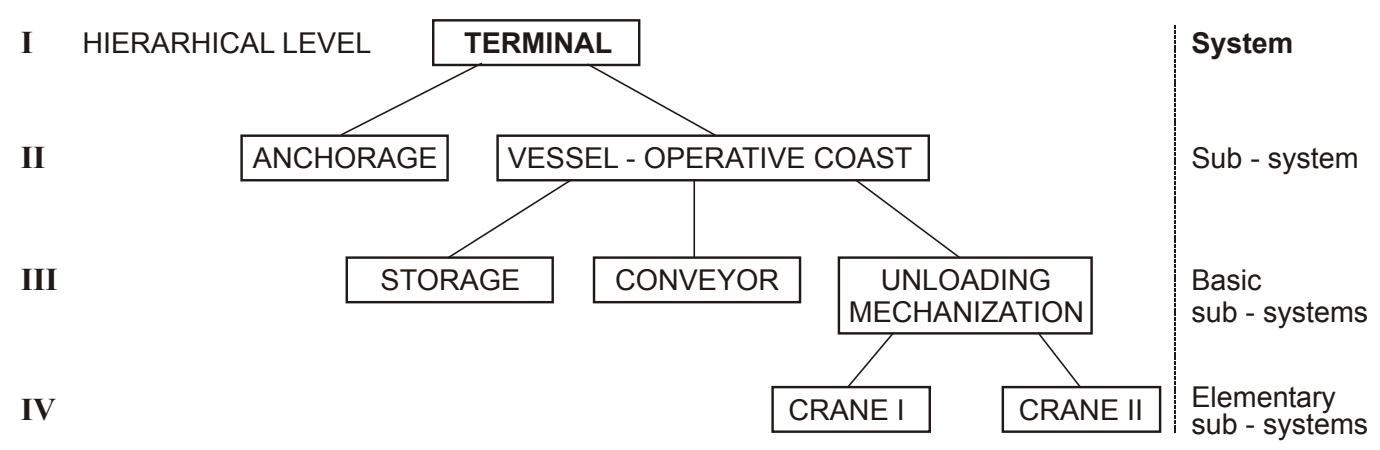

Fig. 2. Hierarchical structure and levels of river terminal

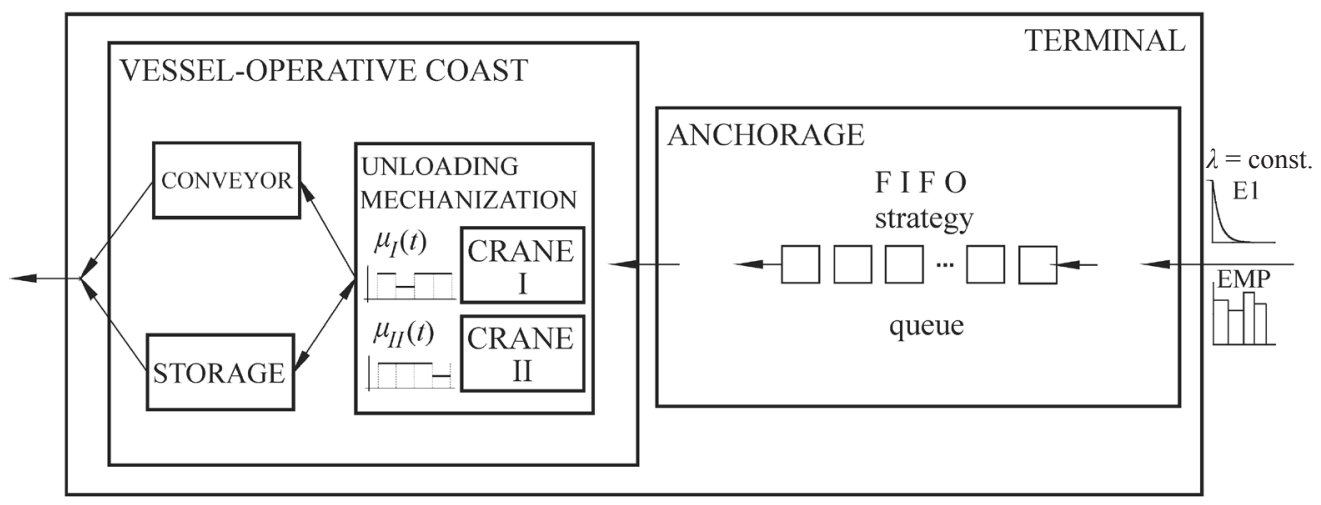

Fig. 3. Servicing and material flow in river terminal

Table 1. Data about bulk materials which are to be unloaded [2]

\begin{tabular}{|c|c|c|c|c|c|}
\hline $\begin{array}{c}\text { Type of } \\
\text { material }\end{array}$ & $\begin{array}{c}\text { Absolute frequency } \\
\text { of material } \\
\text { appearance [t/year] }\end{array}$ & $\begin{array}{c}\text { Relative } \\
\text { frequency } \\
\text { of material } \\
\text { appearance }\end{array}$ & $\begin{array}{c}\text { Density of } \\
\text { material } \\
\rho_{m}\left[\mathrm{t} / \mathrm{m}^{3}\right]\end{array}$ & Grab type & $\begin{array}{c}\text { Coefficient of } \\
\text { grab loading } \\
k_{g}\end{array}$ \\
\hline iron ore & 900000 & 0.75 & $2.2 ; 2.5 ; 2.7$ & 1 & $0.8 ; 0.75 ; 0.7$ \\
\hline limestone & 200000 & 0.167 & $1.43 \div 1.6$ & 2 & 0.8 \\
\hline coal & 100000 & 0.083 & 0.8 & 2 & 0.9 \\
\hline
\end{tabular}

Table 2. Grabs - technical data [2]

\begin{tabular}{|c|c|c|c|c|c|}
\hline Grab type & Material type & $\begin{array}{c}\text { Volume } V_{g} \\
{\left[\mathrm{~m}^{3}\right]}\end{array}$ & $\begin{array}{c}\text { Mass } \\
{[\mathrm{kg}]}\end{array}$ & $\begin{array}{c}\text { Dimensions } \\
L \times B[\mathrm{~m}]\end{array}$ & $\begin{array}{c}\text { Needed crane } \\
\text { capacity }[\mathrm{t}]\end{array}$ \\
\hline 1 & iron ore & 3.2 & 3600 & $3.5 \times 1.75$ & 12.5 \\
\hline 2 & limestone, coal & 5 & 3750 & $4.25 \times 2$ & 12.5 \\
\hline
\end{tabular}

river terminal and technological connections between sub-systems, due to material flow, are shown in Fig. 3.

The presented models cover a different kind of material in the vessels (Table 1, empirical distribution of material appearance - EMP), which are to be unloaded with different kind of grabs
(Table 2). Vessel type and number of vessels in the composition are given in Table 3.

Only one type of vessels and one composition size is used in modelling because of limitations of the basic queuing theory models.

Given quantities of material (Table 1) are planned for the period of one year of work and will 
be the starting values for the on-going experiment i.e. calculation of average arrival rate $(\lambda)$, while other technical data are used for calculating different average servicing rates $(\mu)$.

Table 3. Vessel composition - technical data [2]

\begin{tabular}{|c|c|c|}
\hline $\begin{array}{c}\text { Vessel } \\
\text { type }\end{array}$ & $\begin{array}{c}\text { Capacity }\left(Q_{v}\right)[\mathrm{t}] / \\
\text { Volume }\left(V_{v}\right)\left[\mathrm{m}^{3}\right]\end{array}$ & $\begin{array}{c}\text { No. of vessels in } \\
\text { composition }\end{array}$ \\
\hline 71701 & $1700 / 1700$ & 6 \\
\hline
\end{tabular}

\subsection{Sub-System »Anchorage«}

The purpose of the "anchorage" subsystem is to accept and accommodate vessels. Anchorage is the queue, where vessels are waiting for unloading. Probability that two vessel compositions arrive at the same time is extremely low and can be neglected, due to scheduling of arrivals of the vessel compositions. Inter-arrival time of the vessel compositions is randomly variable, considering weather conditions, river traffic etc. [2].

On the basis of the number of empty places at the anchorage, the decision of acceptance of the vessel composition is made, which means that when there is not enough space at the anchorage for the whole composition it can not be accepted to the system. Vessels are taken to servicing - unloading from the anchorage by the FIFO discipline [3].

\subsection{The »Vessel - Operative Coast « Sub-System}

The "vessel - operative coast" sub-system, with its hierarchically lower systems, is in charge of vessel unloading. Unloading of the vessel consists of the two stages. The first stage is free digging up to approximately $80 \%$ (free digging rate $\mu_{f d}$ ) of material to be unloaded from the vessel and the second stage is cleaning of the vessel until it is empty (cleaning rate $\mu_{c l}$ ). After the $80 \%$ of the material is unloaded from the vessel, the thickness of the material in the vessel is too small, so there is the danger that the grab can damage the vessel. Therefore, unloading must be changed to cleaning [2].

The model only identifies the existence of the "storage " basic sub-system and outlines the connections with the other two basic sub-systems in the environment of the $/$ vessel - operative coast « sub-system. The purpose of "storage" is to accept the material from the »unloading mechanization « when the means of land transport (highway and railway) are not available. Material from »storage « is brought out by means of land transport when they are available or by »unloading mechanization « using a »conveyor « when there is no vessel in the system and the means of land transport are available.

The »conveyor « basic sub-system consists of more mutually connected belt conveyors. The purpose of the »conveyor « is to accept the material from "unloading mechanization« (through the hopper on the unloading bridge) and to pass it to the available means of land transport. The »conveyor $«$ has the priority due to material flow against »storage« i.e. if the means of land transport are available all unloaded material goes through it.

The Basic sub-system "unloading mechanization « contains two elementary subsystems »crane«. The "Crane" uses different grabs for unloading different types of materials from the vessel (Table 1 and 2). The purpose of »unloading mechanization « is to unload the material from a vessel to one of the two remaining basic subsystems the »conveyor « or the »storage«.

The main focus of this paper is in different modelling of the basic sub-system »unloading mechanization«. Two models are developed, which differ in manner of modelling »unloading mechanization «.

In the first manner (Model 1), two elementary sub-systems "crane« work independently, which means that the first "crane" unloads vessel on berth 1 and can not move to berth 2, while second "crane" unloads vessel on the berth 2 and can not move to berth 1 . When unloading of the vessel on its berth is finished the "crane" is idle i.e. the "crane" is waiting for tugboat to drag empty vessel to anchorage and drag the loaded vessel from the anchorage to an empty berth.

In the second manner (Model 2), the two elementary sub-systems »crane«, work with a strategy. The strategy is developed and designed according to the criteria stipulating that at least one »crane" works with a free digging rate throughout the unloading process. The »unloading mechanization « strategy of work is as follows: 
both »crane«-s are unloading the vessel together, for example, on berth 1 (Fig. 4a - Phase I) until approximately $80 \%$ of the material is unloaded (free digging rate $\mu_{I}=\mu_{I I}=\mu_{f d}$ ). After that the "crane" II goes to the second berth and starts unloading the vessel on berth 2 with free digging rate $\mu_{I I}=\mu_{f d}$. During this "crane" I is cleaning the vessel docked on berth 1 with a cleaning rate $\mu_{I}=$ $\mu_{c l}$ (Fig. 4b - Phase II).

After cleaning the vessel docked on berth 1 , »crane« I goes to berth 2 and starts unloading the vessel with a free digging rate $\mu_{I}=\mu_{f d}$, together with "crane" II (Fig. 4c - Phase III). At that moment a tugboat drags the empty vessel from berth 1 to the anchorage and drags the loaded vessel back from the anchorage to the empty berth 1 , meaning that the time needed for vessel dragging is not wasted but overlapped with the engagement of "crane" I for unloading on berth 2 and does not need to be taken into consideration. When approximately $80 \%$ of the material form vessel docked on berth 2 is unloaded, "crane" I goes to berth 1 and starts unloading the vessel with a free digging rate $\mu_{f d}$. During this "crane" II is cleaning the vessel docked on berth 2 with a cleaning rate $\mu_{c l}$ (Fig. $4 \mathrm{~d}$ - Phase IV). After cleaning the vessel docked on berth 2 is finished, the "crane" II joins the "crane" I on berth 1 and starts unloading the vessel with a free digging rate $\mu_{f d}$. Also, at that moment the tugboat is dragging the empty and loaded vessel from/to berth 2 , which means that this time overlapps with engagement of "crane" II for unloading on berth 1 and does not need to be taken into consideration. In this way, the unloading of the vessels is repeated cyclically.

The »crane« elementary sub-systems i.e. unloading bridges using a grab and hopper on it presents knot points of unloading terminals, and in most cases the »bottle necks«, so they are a basic prerequisite for optimal work of the whole terminal for bulk cargo unloading. Due to this fact the modelling of the "crane" must be done at the beginning of the modelling of the river terminal and must be performed with great detail [3].

\subsection{The Elementary Sub-System »Crane«}

The unloading of the bulk cargo can be done with continuous unloading devices, or with
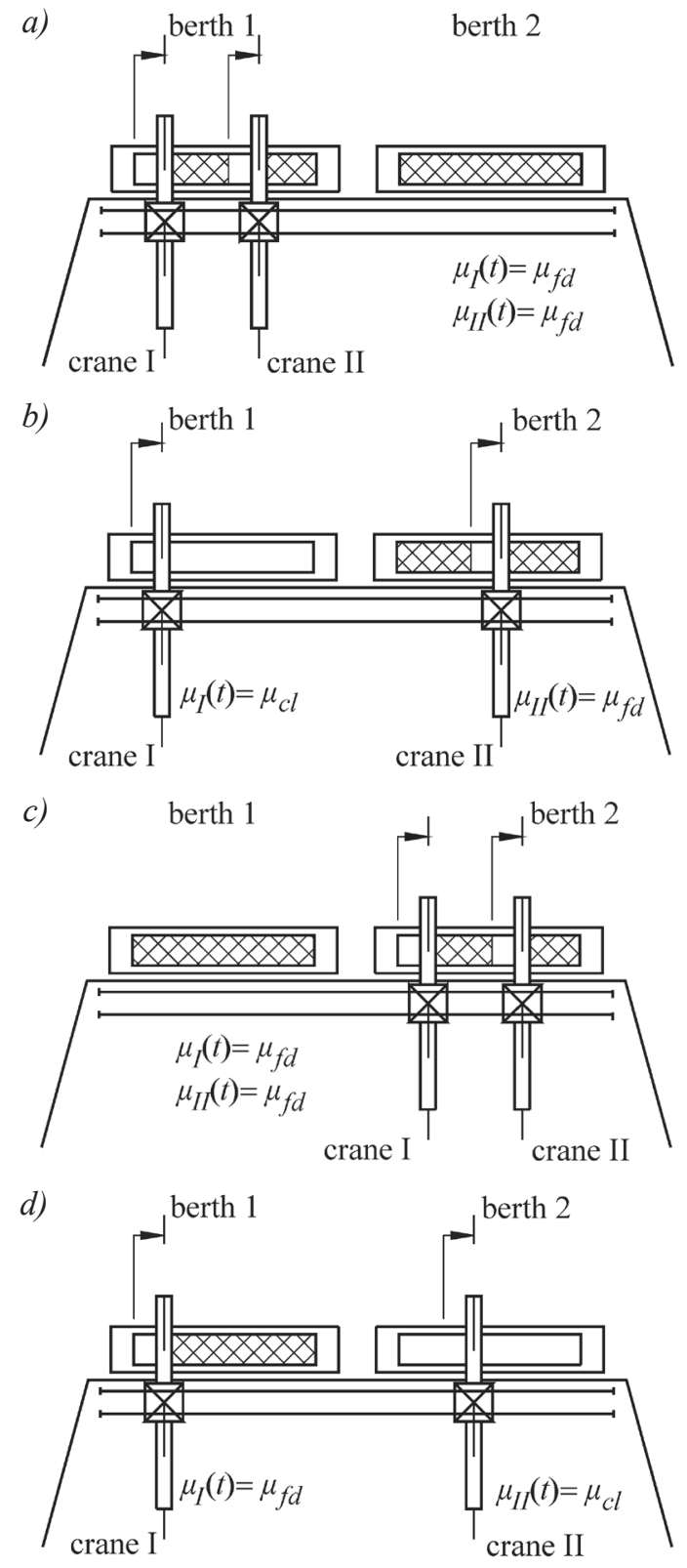

Fig. 4. The Sub-system "vessel - operative coast" work with a strategy; a) Phase I, b) Phase II c) Phase III, d) Phase VI

grab crane devices. This paper considers only grab crane devices (Fig. 5).

The unloading cycle of grab crane devices consists of: material grabbing from the vessel, loaded grab transfer from the vessel to the receiving hopper, discharging and empty grab transfer from the hopper to the vessel. Full 
automation of the unloading process of the grab crane devices is possible but very expensive. On the other hand, the crane operator can not repeat the optimal unloading cycle in time. The only practical feasible solution is to introduce the halfautomatic unloading cycle i.e. unloading cycle. This cycle consists of a manual part, where the crane operator controls the grab moving, and an automatic part in which the computer controls the grab moving according to the given algorithm. Only the automatic part of the unloading cycle can be modelled and optimized [10].

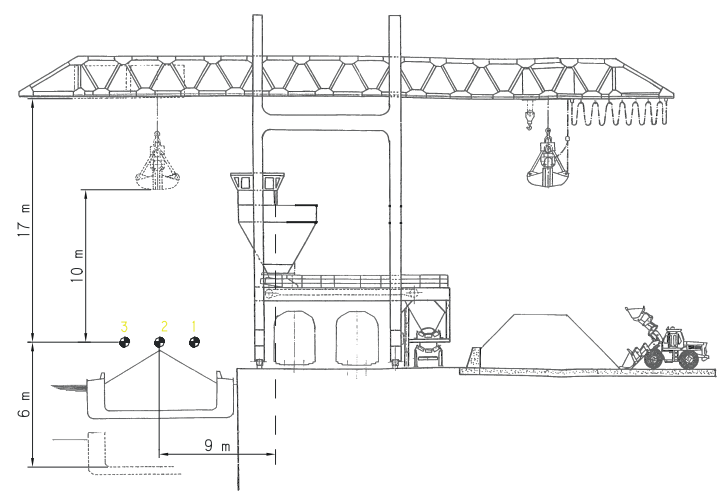

Fig. 5. Elementary sub-system »crane» with grab

The manual part of the unloading cycle consists of the empty grab lowering to material surface in the vessel, from one of the three points of the end of the automatic part of the unloading cycle (Fig. 5), material grabbing and loaded grab hoisting to one of the three points of the beginning of the automatic part of the unloading cycle. The automatic part of the unloading cycle consists of a grab transfer from one of the three points of the beginning of the automatic part of the unloading cycle to the hopper, grab discharging and empty grab return transfer from the hopper to the one of the three possible points of the end of the automatic part of the unloading cycle. The begin/ end point position of the automatic part of the unloading cycle depends on a given geometry of the system (Fig. 5), water level, material level in the vessel, etc., and therefore limits the set of possible grab hoisting/lowering and the trolley moving velocities for which it is possible to achieve the automatic part of the unloading cycle.

The main purpose of elementary subsystem crane modelling in this paper is to obtain boundaries for duration of half-automatic unloading cycle. The duration of the unloading cycle is: $t_{u c}=51.87$ to $63.87 \mathrm{~s}$ [2] and [3].

\section{QUEUING THEORY BASED MODEL OF TERMINAL FOR BULK CARGO UNLOADING}

The terminal for bulk cargo unloading will be modelled using multi channel queuing model with finite queue and bulk arrival of the units [4] and [6].

System characteristics:

- there are $c=2$ servicing channels i.e. elementary sub-systems "crane",

- queue size is $m=32$ places i.e. anchorage capacity (maximal number of vessels that can wait for unloading),

- units are arriving into system in groups of $r=$ 6 i.e. the number of vessels in a composition (see Table 3),

- arrival rate $(\lambda)$ of the vessel compositions is constant i.e. Exponentially distributed interarrival times - E1 (see 2.1), i.e.

$$
\lambda_{k}=\left\{\begin{array}{ll}
\lambda & k=0,1, \ldots, c+m-r \\
0 & k>c+m-r
\end{array},\right.
$$

- system servicing rate $(\mu)$ is constant if two elementary sub-systems »crane« are working independently (see 2.2.1), while if two elementary sub-systems »crane « are working with a strategy, then the servicing rate changes in time (see 2.2.2),

- queue discipline is FIFO (First-In-First-Out),

- Kendall notation of this system is $\mathrm{M}^{[6]}$ $/ \mathrm{M} / 2 / 32$.

System state is defined according to the number of vessels in the system. State-transitionrate diagram of described system is shown in Fig. 6.

If arriving vessel composition finds that all "crane"-s are idle, then whole composition will be accepted to the system in the following way: two vessels will be immediately taken to unloading while other vessels will be placed at the "anchorage". In the case that one "crane" is busy and one is idle, then the entire composition will be accepted to the system i.e.: one vessel will be immediately taken to unloading while the other vessels will be placed at the "anchorage". If all "crane"-s are busy and the number of free places at the "anchorage" is greater or equal to 
the number of vessels in the composition i.e. 6 , then the whole composition will be accepted to the system and placed in the "anchorage". When all "crane"-s are busy and the number of empty places at the "anchorage" is lower than the size of vessel composition, the whole composition will be cancelled.
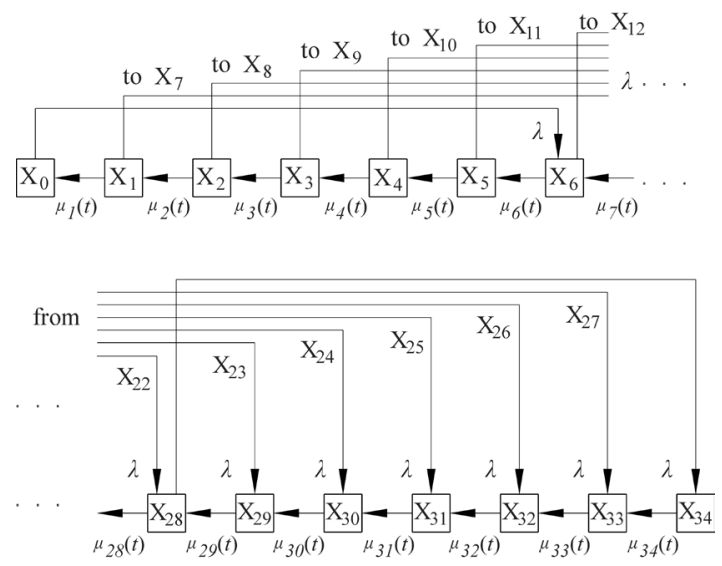

Fig. 6. State-transition-rate diagram of unloading terminal

On the basis of state-transition-rate diagram, (Fig. 6), the system of linear differential equations which describes system state probabilities changing in time can be written as:

$$
\begin{aligned}
& p_{0}^{\prime}(t)=-\lambda \cdot p_{0}(t)+\mu_{1}(t) \cdot p_{1}(t), \\
& p_{1}^{\prime}(t)=-\left[\lambda+\mu_{1}(t)\right] \cdot p_{1}(t)+2 \cdot \mu_{2}(t) \cdot p_{2}(t), \\
& \ldots \\
& p_{i}^{\prime}(t)=-\left[\lambda+\mu_{i}(t)\right] \cdot p_{i}(t)+\mu_{i+1}(t) \cdot p_{i+1}(t), \\
& \text { for } i=2, \ldots, 5, \\
& \ldots \\
& p_{i}^{\prime}(t)=-\left[\lambda+\mu_{i}(t)\right] \cdot p_{i}(t)+ \\
& \quad+\mu_{i+1}(t) \cdot p_{i+1}(t)+\lambda \cdot p_{i-6}(t), \\
& \text { for } i=6, \ldots, 28, \\
& \ldots \\
& \begin{array}{l}
\ldots \\
p_{i}^{\prime}(t)=
\end{array} \\
& \quad+\mu_{i}(t) \cdot p_{i}(t)+ \\
& \text { for } i=29, \ldots, 33, \\
& \ldots \\
& p_{34}^{\prime}(t)=-\mu_{34}(t) \cdot p_{34}(t)+\lambda \cdot p_{28}(t) .
\end{aligned}
$$

Initial conditions for the system of differential Eq. (1) solving are: $p_{0}(0)=1$, $p_{i}(0)=0$ for $i=1, \ldots, 34$, which means that the system is empty at the beginning of the unloading process $(t=0)$.

Modelling of the terminal for bulk cargo unloading will be analysed through the following system performances, according to vessel compositions arrival rate to the system, such as:

- probability of servicing:

$$
P_{\text {ser }}=\frac{1}{t_{e d}} \cdot \int_{0}^{t_{e d}} \sum_{k=0}^{c+m-r} p_{k}(t) \cdot d t,
$$

- probability of a queue:

$$
P_{e q}=\frac{1}{t_{e d}} \cdot \int_{0}^{t_{e d}} \sum_{k=1}^{m} p_{c+k}(t) \cdot d t,
$$

- average number of vessels at the anchorage:

$$
N_{w}=\frac{1}{t_{e d}} \cdot \int_{0}^{t_{e d}} \sum_{k=1}^{m} k \cdot p_{c+k}(t) \cdot d t,
$$

- average time that the vessel spends at the anchorage:

$$
t_{w}=N_{w} / \bar{\lambda},
$$

- average number of vessels in the system:

$$
N_{w s}=\frac{1}{t_{e d}} \cdot \int_{0}^{t_{e d}} \sum_{k=1}^{c+m} k \cdot p_{k}(t) \cdot d t,
$$

- average time that the vessel spends in the system:

$$
t_{w s}=N_{w s} / \bar{\lambda},
$$

where:

$$
\bar{\lambda}=\frac{1}{t_{e d}} \cdot \int_{0}^{t_{e d}} \sum_{k=1}^{c+m-r} \lambda_{k} \cdot p_{k}(t) \cdot d t
$$

is average arrival rate [8], and $t_{e d}$ is experiment duration time.

\subsection{Average Arrival Rate of the Vessel Compositions}

On the basis of statistical data connected to material shipment for unloading terminal, the weather conditions in the terminal area, absolute frequency of material appearance, organization and other conditions and the average arrival rate of the vessel composition can be obtained.

A yearly navigation period (days) on the river in the area of unloading terminal, taking into 
consideration disturbances when navigation is not possible caused by weather conditions like ice ( 38 days), fog ( 6 days) and wind ( 3 days), is:

$t_{n}=365-38-6-3=318$ days [2].

The average needed quantity of material that has to be unloaded in the period of one year is $Q_{y s}=1200000 \mathrm{t} /$ year (see Table 1), meaning that the average daily quantity of shipment material is:

$Q_{d s}=\frac{Q_{y s} \cdot K_{1}}{t_{n}}=\frac{1200000 \cdot 1.2}{318}=4528.3 \mathrm{t} /$ day

where $K_{l}=1.2$ is coefficient of variable shipment [2].

The fact that material is shipped in compositions of six vessels (see Table 3 ) gives the total quantity of material shipped with one composition $\left(Q_{c}\right): Q_{c}=6 \times Q_{v}=6 \times 1700=10200 \mathrm{t}$.

Finally, time interval between two successive arrivals of the vessel compositions is:

$$
\bar{t}_{a r}=\frac{Q_{c}}{Q_{d s}}=\frac{10200}{4528.3}=2.2525 \text { days }
$$

or 54.04 hours, which gives the average arrival rate of $\lambda=0.01851 / \mathrm{h}$.

\subsection{Unloading Rates}

Average time needed for vessel unloading is directly connected to the quantity of the material which has to be unloaded. In order to obtain a free digging rate and cleaning rate it will be assumed that the whole quantity of the material from the vessel can be unloaded with either a free digging and cleaning rate.

The first step in obtaining the average free digging unloading rate is to calculate the number of unloading cycles needed for unloading a vessel with different types of material in it. The number of unloading cycles needed can be calculated using the following expression:

$$
n_{u c}=\left[\frac{Q_{v}}{V_{g} \cdot \rho_{m} \cdot k_{g}}\right],
$$

where:

$Q_{v}=1700[\mathrm{t}]-$ vessel capacity (Table 3$), V_{g}\left[\mathrm{~m}^{3}\right]$ - grab volume for specific type of material (Table 2), $\rho_{m}\left[\mathrm{t} / \mathrm{m}^{3}\right]$ - material density (Table 1$), k_{g}-$ coefficient of grab loading (Table 1).
In Table 4 the needed number of unloading cycles for vessel unloading depending on material type (see Table 1), using Eq. (10) is shown.

Table 4. Number of unloading cycles needed for vessel unloading

\begin{tabular}{|c|c|c|c|c|}
\hline Material & $\begin{array}{c}\text { Material } \\
\text { density } \\
\rho_{m} \\
{\left[\mathrm{t} / \mathrm{m}^{3}\right]}\end{array}$ & $\begin{array}{c}\text { Grab } \\
\text { volume } \\
V_{g} \\
{\left[\mathrm{~m}^{3}\right]}\end{array}$ & $\begin{array}{c}\text { Coeffi- } \\
\text { cient } \\
\text { of grab } \\
\text { loading } \\
k_{g}\end{array}$ & $\begin{array}{c}\text { No. of } \\
\text { unload. } \\
\text { cycles }\end{array}$ \\
\hline iron ore & 2.7 & 3.2 & 0.7 & 281 \\
\hline iron ore & 2.5 & 3.2 & 0.75 & 283 \\
\hline iron ore & 2.2 & 3.2 & 0.8 & 302 \\
\hline limestone & $\approx 1.52$ & 5 & 0.8 & 280 \\
\hline coal & 0.8 & 5 & 0.9 & 378 \\
\hline
\end{tabular}

The average time for unloading vessels with different material types, under the assumption that: the whole vessel can be unloaded with a free digging rate (average unloading cycle time $t_{u c}=0.9645 \mathrm{~min}$, see Chapter 1.3) and that relative frequencies of the appearance of iron ore of different density are equal and upon relative frequency of material appearance (Table 1), is:

$\bar{t}_{v u}^{f d}=(0.25 \cdot 281+0.25 \cdot 283+0.25 \cdot 302+$ $+0.167 \cdot 280+0.083 \cdot 378) \cdot 0.9645=4.7362 \mathrm{~h}$,

which leads to average free digging unloading rate $\mu_{f d}=1 / 4.7362=0.21114 \mathrm{l} / \mathrm{h}$.

During the vessel cleaning approximately $20 \%$ of material has to be unloaded (see Chapter 1.2 ) and this operation (cleaning), according to experience data [2], lasts 75 minutes. Therefore, virtual time needed for unloading all the material from the vessel using such unloading regime (vessel cleaning) is $\bar{t}_{v u}^{c l}=5.75=375$ minutes or $6.25 \mathrm{~h}$, which leads to the average cleaning rate as $\mu_{c l}=1 / 6.25=0.161 / \mathrm{h}$.

\subsubsection{Unloading Rate in the Case of Separate "Crane" Work ("Work without Strategy-Model 1)}

The average time needed for vessel unloading, in the case of separate "crane"-s work - sw, can be obtained as a sum of the average free digging time and average cleaning vessel time as: 


$$
\begin{aligned}
\bar{t}_{v u}^{s w} & =0.8 \cdot \bar{t}_{v u}^{f d}+0.2 \cdot \bar{t}_{v u}^{c l}= \\
& =0.8 \cdot 4.7362+0.2 \cdot 6.25=5.0390
\end{aligned}
$$

The only way in which time needed for a tugboat to drag an empty vessel from berth to anchorage and drag a loaded vessel back from the anchorage to empty berth, can be incorporated in a mathematical model is through servicing (unloading) time i.e. unloading rate. According to experience, time needed for vessel dragging in both ways is approximately $\bar{t}_{d}=60$ minutes [2], which gives a fictive vessel unloading time of 6.0390 hours.

Finally, the fictive average vessel unloading rate is $\mu_{a v}=1 / 6.039=0.16559 \mathrm{l} / \mathrm{h}$.

The unloading rate, in the case of separate "crane"-s work, depending on the system state has the following form:

$$
\mu_{i}(t)=\left\{\begin{array}{cc}
\mu_{a v} & i=1 \\
2 \cdot \mu_{a v} & i \in[2, \ldots, 34]
\end{array},\right.
$$

\subsubsection{Unloading Rate in the Case of "Crane"-s Work with Strategy (Model 2)}

The procedure of vessel unloading in the case of "crane"-s work with strategy is presented in chapter 2.2. According to this, duration of periods at which "crane"-s are unloading vessels with free digging rare $\mu_{f d}$ or with cleaning rate $\mu_{c l}$ can be determined in following way (Fig. 7):

- during the unloading of the first vessel (before this system was empty) both "crane"-s unload the vessel with a free digging rate $\mu_{f d}$ until each "crane" unloads $40 \%$ of material from the vessel on berth 1 . The time needed for unloading $40 \%$ of material from vessel is approximately 114 minutes.

- $\quad$ after that, "crane" I cleans the vessel for 75 minutes with cleaning rate $\mu_{c l}$, while "crane" II goes to berth 2 and starts to unload the vessel with free digging rate $\mu_{f d}$. In 75 minutes (vessel cleaning time) "crane" II on berth 2 , with free digging rate $\mu_{f d}$ will unload $26.5 \%$ of material from vessel.

- after the cleaning of the vessel on berth 1 is finished, "crane" I goes to berth 2 and starts unloading. At this moment each "crane" has to unload another $(100-26.5-20) / 2=$
$26.75 \%$ of material with free digging rate $\mu_{f d}$, which will last another 76 minutes.

- $\quad$ after that, "crane" II cleans the vessel, for 75 minutes on berth 2 with a cleaning rate $\mu_{c l}$, while "crane" I goes to berth 1 and starts unloading the vessel with a free digging rate $\mu_{f d}$.

- $\quad$ after the cleaning of the vessel on berth 2 is finished, "crane" II goes to berth 1 and starts unloading. At this moment each "crane" has to unload another $(100-26.5-20) / 2=26.75 \%$ of material with free digging rate $\mu_{f d}$, which will last for another 76 minutes. Afterwards, the unloading rates change cyclically.

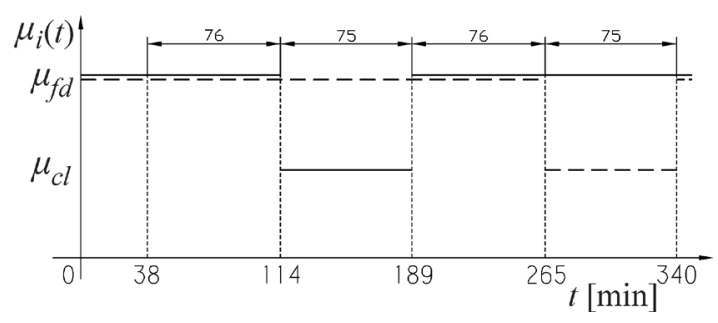

Fig. 7. Change of vessel unloading rate $\mu(t)$

In the described "crane"-s work with a strategy, three periods can be noticed:

- I period: one "crane" alone unload the vessel with free digging rate $\mu_{f d}$,

- II period: both "crane"-s unload the vessel with free digging rate $\mu_{f d}$,

- III period: one "crane" alone cleans the vessel with a cleaning rate $\mu_{c l}$.

Time interval from the beginning of unloading to 114 minute can be divided into two parts, i.e. the first part which lasts 38 minutes and the second which lasts 76 minutes. The first part (38 minutes) replaces "I period" in the work of each "crane", because the system is empty at the beginning and both "crane"-s start to unload the full vessel, so the time needed is equal to one half of duration of "crane" work in "I period".

On the basis of the above mentioned, it is possible to establish the change in the unloading rate as a function of time for each "crane". The change of unloading rates as a function of time is a discontinuous function. The change of the unloading rate per time (minutes) for "crane" I, $\mu_{I}(t)$, takes the following form: (Fig. 8) 


$$
\mu_{I}(t)= \begin{cases}\mu_{f d} ; & 0<t^{\prime} \leq 76 ; \\ \mu_{c l} ; & 76<t^{\prime} \leq 151 ; \\ \mu_{f d} ; & 151<t^{\prime} \leq 302 ;\end{cases}
$$

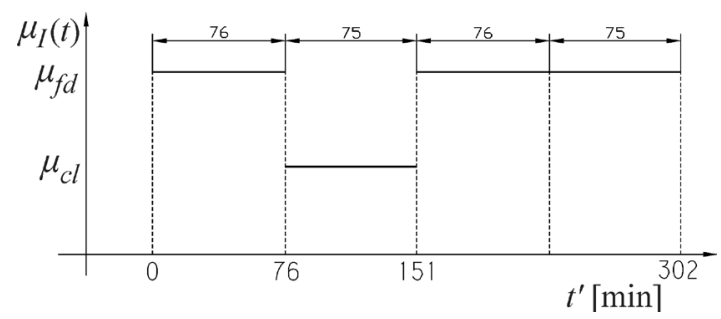

Fig. 8. Change of unloading rate of "crane" I per time

The change of the unloading rate per time (minutes) for "crane" II $\mu_{I I}(t)$, has the following form (Fig. 9):

$$
\mu_{I I}(t)= \begin{cases}\mu_{f d} ; & 0<t^{\prime} \leq 227 ; \\ \mu_{c l} ; & 227<t^{\prime} \leq 302 ;\end{cases}
$$

where: $t$ ' $[\mathrm{min}]$ - is reduced time to "I period" of "crane"-s work and can be calculated as:

$$
t^{\prime}=(t-38)-\left[\frac{t-38}{\tau}\right] \cdot \tau ;
$$

where: $t$ [min] current time in the system, and $\tau \cong$ 302 min - duration of interval in "crane"-s work which it is successively repeated, in the case of "crane"-s work with strategy, (I period $+2 \times$ II period + III period).

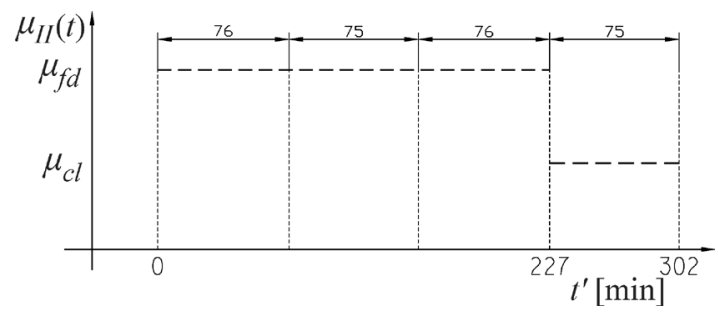

Fig. 9. Change of unloading rate of "crane" II per time

At the end the change of vessel unloading rate, in the case of "crane"-s working with a strategy, can be obtained as (Fig. 7):

$$
\mu_{i}(t)=\mu_{I}(t)+\mu_{I I}(t), i=1, \ldots, 34 .
$$

\section{RESULTS OF TERMINAL MODELLING}

Initial conditions for system (unloading terminal) analysis are that the system (anchorage) is empty and all servicing facilities (crane-s) are idle. The results are obtained for basic arrival rate of the vessel compositions to the system $(\lambda=$ $0.01851 / \mathrm{h}$ ) and its increase by $1.5,2,2.5,3,3.5$ and 4 times, for one year period ( $t_{e d}=8760$ hours).

The results of the terminal modelling, according to vessel compositions arrival rate to the system are: probability of servicing $P_{\text {ser }}$ (Fig. 10), probability of existing a queue $P_{e q}$ (Fig. 11), the average number of vessels at the "anchorage" $N_{w}$ (Fig. 12), average time that the vessel spends at the anchorage $t_{w}$ (Fig. 13), the average number of vessels in the system $N_{w s}$ (Fig. 14), the average time that the vessel spends in the system $t_{w s}$ (Fig. $15)$

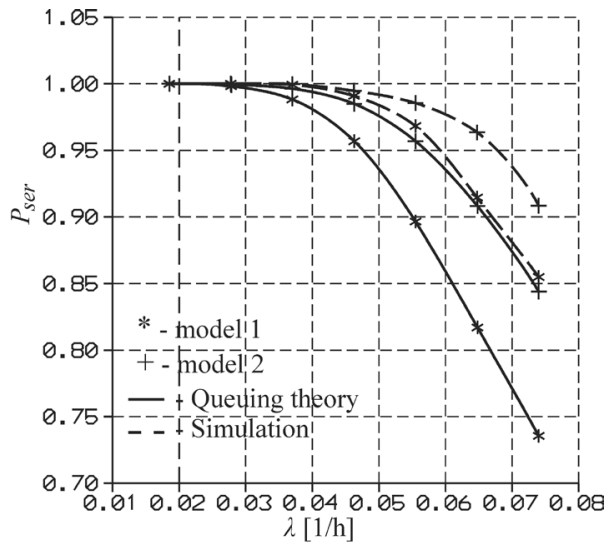

Fig. 10. Probability of servicing

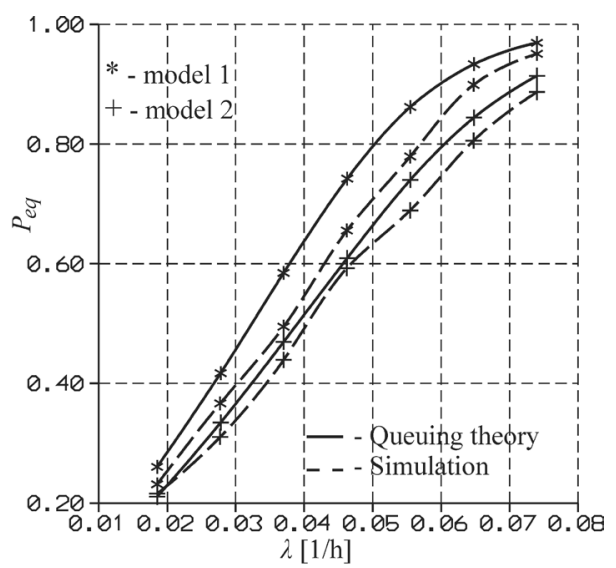

Fig. 11. Probability of a queue 


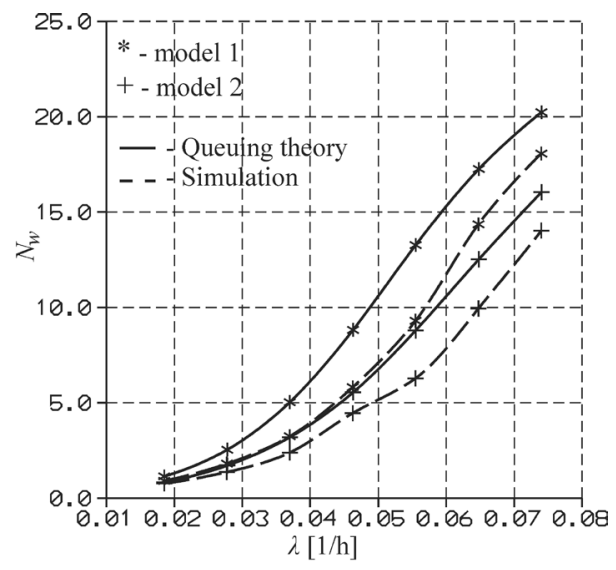

Fig. 12. Average number of vessels at the anchorage

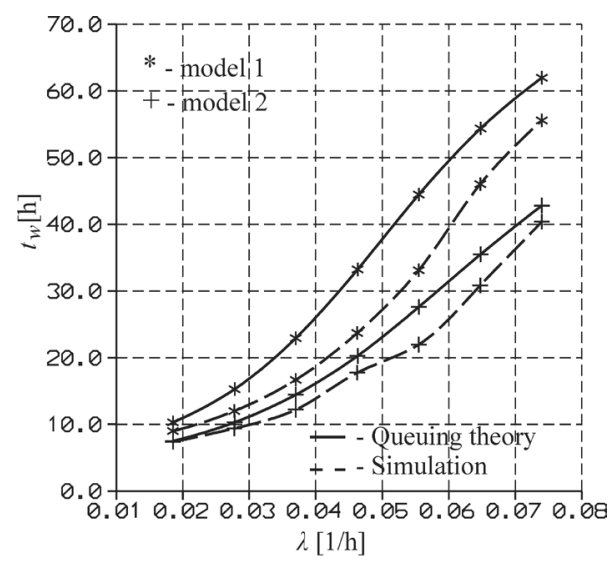

Fig. 13. Average time that vessel spends at the anchorage

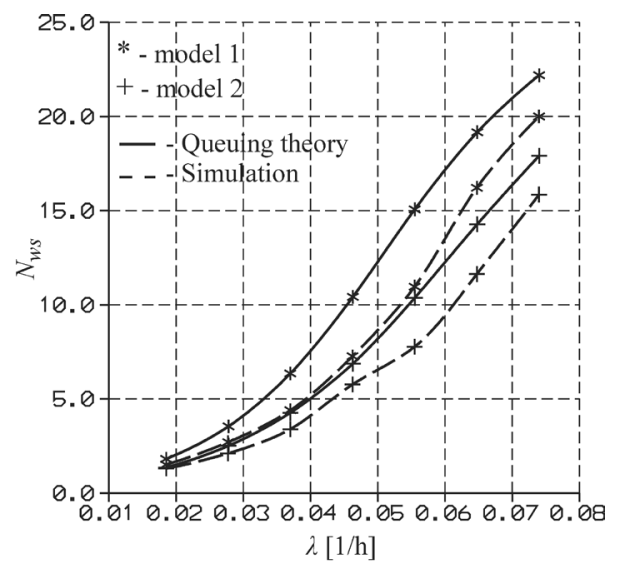

Fig. 14. Average number of vessels in the system

When work of "unloading mechanization" is modelled without strategy (model 1), the results in Figs. 10 to 15 are represented by "_*_“, while when work of "unloading mechanization" is modelled with a strategy (model 2), the results in Figs. 10 to 15 are represented by "-+-_".

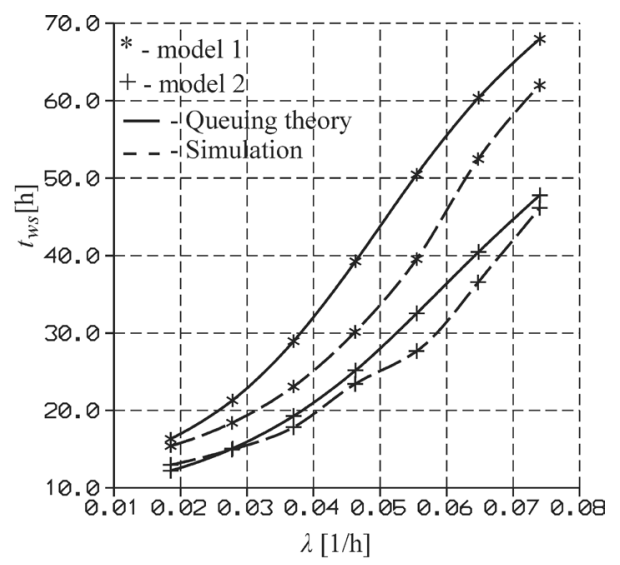

Fig. 15. Average time that vessel spends in the system

Figs. 10 to 15 alongside show the obtained results using the queuing theory and the results of simulation modelling given in [3].

It has been shown that the characteristics of the obtained results using the queuing theory and simulation are the same.

The results differ due to the limitations of the queuing theory as:

- The servicing process is restricted to one phase;

- The average vessel unloading time is fixed;

- The influence of different type of materials; on vessel unloading time, is mathematically calculated as average;

- The vessel composition is fixed to one size;

- Only one vessel size is used.

The presented simulation results also differ because the servicing process is divided into three phases and all other parameters are presented by appropriate stochastic distributions [3].

All new results are on the safe side so that by using them the designer will deal with lover system capacity.

A high probability of servicing vessel compositions ( 0.95 and higher) is required in the work of terminals for bulk cargo unloading. If the system is modelled by the queuing theory, using model 1, then the maximal increase of the basic arrival rate of vessel compositions to the system 
can be 2.5 times, while if the system is modelled using simulation the maximal increase is 3 times. When model 2 is used the basic arrival rate of vessel compositions to the system can be 3 times higher using the queuing theory modelling and 3.5 times using simulation modelling.

The above presented results, once again, show that the unloading capacity of the terminal for bulk cargo unloading is higher when "unloading mechanization" works with a strategy, for the same capital costs. The same capital costs means: the same number of unloading devices - "crane"-s which is reflected in the length of the operative coast, the same capacity of the anchorage etc.

\section{CONCLUSION}

During the sailing period the river terminal for bulk cargo unloading works 24 hours, seven days a week. Even a very small cut-down of the duration time needed for vessel unloading, can save the energy needed for unloading and can minimize expenses which are caused by unsatisfactory servicing rate i.e. stay of the vessels at the system (terminal) longer than it is allowed [3].

The paper discusses the results of analytical modelling using the queuing theory and compares them with the simulation modelling result previously given in [3] and underlines and explains their differences.

The task of the engineers involved in design process is to define the capacity of the system, so that system input/output can be estimated.

Due to this, there is a need for developing a simpler and quicker design approach with appropriate accuracy which is the mean reason why the presented analytical model, using the queuing theory, has been developed. In other words, the newly developed model can replace the previous one, which was a more complicated simulation model at the beginning of the system design process.

The obtained results, using the queuing theory, can be used at the beginning of the design process for the first predictions of the system boundaries when rough estimations of the system behaviour is needed, while simulation modelling results are to be used in the phase of detail design process.

\section{REFERENCES}

[1] Agerschou, H., Lundgren, H., Sørensen, T. (1983). Planning and design of ports and marine terminals. John Wiley \& Sons, New York.

[2] Bugaric, U. (1996). Contribution to optimization of bulk cargo unloading processes at river ports - M.Sc. Thesis, Belgrade: Faculty of Mechanical engineering.

[3] Bugaric, U., Petrovic, D. (2007). Increasing the capacity of terminal for bulk cargo unloading. Simulation Modelling Practice and Theory, vol. 15, p. 1366-1381.

[4] Clymer, J. (1990). System analysis using simulation and Markov models. Prentice-Hall International Inc., New Jersey.

[5] Comer, E., Taborga, P.N. (1987). Port simulation model (PORTSIM) - User's manual. The World Bank, Washington.

[6] Cooper, R. (1981). Introduction to queuing theory. North Holland, New York.

[7] El Sheikh, A.A., Paul, J.R., Harding, S.A., Balmer, W.D. (1987). A MicrocomputerBased Simulation Study of a port. J. Opl. Res. Soc., vol. 38, p. 673-681.

[8] Hiller, F.S., Lieberman, G.J. (2001). Introduction to operations research (7th edition). McGraw-Hill, New York.

[9] Kondratowicz, J.L. (1990). Simulation methodology for intermodail freight transportation terminals. Simulation, vol. 51, p. 49-57.

[10] Oyler, F. (1977). Handling of bulk solids in ocean ports. Wohlbier, R.H. (ed.), Stacking Blending Reclaiming. Trans Tech Publications, Clausthal.

[11] Park, S.C., Noh, D.Y. (1987). A port simulation model for bulk cargo operations. Simulation, vol. 48, p. 236-246.

[12] Sinowczik, M. (1977). EUROPORT - A bulk handling plant for iron ores and pallets. Wohlbier, R.H. (ed.), Stacking Blending Reclaiming. Trans Tech Publications, Clausthal. 